\title{
Randomised controlled trial of computer-held medical records in hypertensive patients
}

\author{
C J BULPITT, L J BEILIN, E C COLES, C T DOLLERY, B F JOHNSON, \\ A D MUNRO-FAURE, S C TURNER
}

British Medical fournal, 1976, 1, 677-679

\section{Summary}

A total of 278 hypertensive patients in three clinics were randomly allocated to have their medical records held in a computer system (136) or on standard hospital notes (142). For the computer system the doctor completed a structured input form, and the information on symptoms, physical findings, and diagnoses was more complete than that in the standard notes. This resulted in certain symptoms and risk factors being recognised more often when the computer system was used. The hypertension clinics' routines were not disrupted by the introduction of a computer-held system, and follow-up consultation times were not affected by the type of records kept, although the first consultation took eight minutes longer when computer documents were completed.

The patients remained in the trial for one year and clinical management was assessed from blood pressure

Department of Medical Statistics and Epidemiology, London School of Hygiene and Tropical Medicine, London

C J BULPITT, MD, MSC, senior lecturer in epidemiology and honorary consultant physician at Hammersmith Hospital

Department of Regius Professor of Medicine, Radcliffe Infirmary, Oxford

L J BEILIN, MD, FRCP, honorary consultant physician and clinical reader

Division of Computing and Statistics, Medical Research Council Clinical Research Centre, Northwick Park Hospital, Harrow, Middlesex

E C COLES, MB, MTECH, member of scientific staff

$S$ C TURNER, SRN, senior programmer

Department of Clinical Pharmacology, Royal Postgraduate Medical School, Hammersmith Hospital, London

C T DOLLERY, MB, FRCP, professor of clinical pharmacology

Department of Renal Medicine, King's College Hospital, London A D MUNRO-FAURE, MB, FRCPC, honorary clinical assistant B F JOHNSON, MB, MRCP, honorary clinical assistant control, drop-out rates, and the frequency of performing investigations. These estimates of management showed no significant difference between the two groups, but the attempt to tailor the computer system to help management made the system acceptable to the doctors using it. The computer system continues to be used and is providing data for research into hypertension.

\section{Introduction}

A computer-based system for recording clinical information on hypertensive patients has been described in detail. ${ }^{2}{ }^{2}$ The system is designed to allow the doctor to record his usual clinical notes but in a structured format to allow encoding by computer and the subsequent retrieval and analysis of information.

The system is also designed to help with the clinical management of each patient and a summary document is produced for each follow-up visit which reminds the clinician of important clinical features, including the diagnoses made, past blood pressures, present treatment and symptoms, investigations ordered at the last visit, and risk factors present such as a history of smoking or high serum cholesterol levels. As the system is designed to help both research and management we tried to answer two questions by a randomised controlled trial: firstly, does the system aid the collection of data for research ? Secondly, to what extent does the system influence patient management and the running of hypertensive clinics? We report here the results of this trial.

\section{Methods}

Hypertension clinics at Hammersmith Hospital, Radcliffe Infirmary, and King's College Hospital participated in the trial. Until certain target numbers were reached (over six to eight months) every patient referred to these clinics with a diagnosis of hypertension was randomly allocated to having his records kept either within the computer system or on the standard medical records of the particular hospital. After the initial visits the doctors could not easily identify whether a particular patient was included in the trial. Both computer notes and standard notes were used at the three clinics before and after the trial, and the notes did not record participation in the trial as this informa- 
tion was held centrally. Every trial patient remained in the study for one year after his first visit. During the trial consultation times at the Radcliffe Infirmary were assessed by the Organisation and Methods Productivity Services Unit of the Oxford Regional Hospital Board and United Oxford Hospitals. ${ }^{3}$

At the end of the trial the clinical information from the standard case notes was transferred to the computer input documents to facilitate a comparison of the data recorded on the two systems. In the case of computer-held records, clinic clerks entered the results of investigations in the computer documents. In the standard notes investigation results were placed in as report forms and sometimes transcribed by the doctor on to the clinical history pages. The presence of an investigation report form in the standard notes was accepted as evidence that the result had been recorded. But during a preliminary analysis we found that, owing to deficiencies of filing, investigation results were often not present in the standard notes and similarly had not been transcribed onto the computer-held records. To permit a reliable comparison, therefore, missing investigation results were obtained from the laboratories to ensure complete recording of results.

All patients not discharged, dead, or attending the clinic at the end of one year were contacted directly or via their general practitioner. A patient was judged to be lost to follow-up two years after his first visit if he had not attended the clinic for a year.

Blood pressure control during follow-up was assessed by computing the average pressure for the patient during each of the four threemonth periods in the trial.

\section{Results}

COMPARABILITY OF TWO GROUPS OF PATIENTS

A total of 278 outpatients were recruited to the trial, 136 having computer-held records and 142 standard notes. One-hundred-andforty-six presented to the Hammersmith clinic ( 72 allocated to computer-held records), 93 to the Radcliffe Infirmary ( 45 computerheld), and 39 to King's College Hospital (19 computer-held). The patients with computer-held records had an average age of 51 years and a lying blood pressure of $178 / 105 \mathrm{~mm} \mathrm{Hg}$, and $56^{\circ}{ }_{\circ}^{\prime}$ were women. The control patients had an average age of 48 years and a lying pressure of $177 / 106 \mathrm{~mm} \mathrm{Hg}$, and $53 \%$ were women. The two groups were not statistically different in these respects.

\section{CONTENT OF COMPUTER-HELD RECORDS}

Fifteen items of the history considered important in hypertension were designated key symptoms, and the computer document completed at the patient's first visit included questions about the presence or absence of these symptoms. Table I lists these key symptoms and shows that in every instance significantly more information was recorded when the structured computer document was used $(\mathrm{P}<$

TABLE I-Comparison of histories recorded in standard notes and on computerheld record

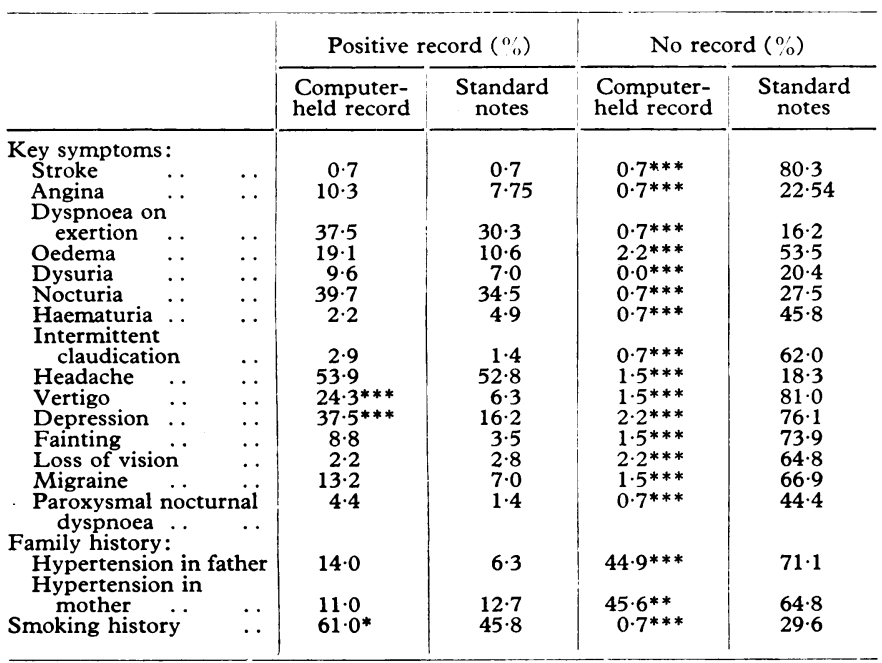

Significance of difference computer-held $v$ standard records: $* \mathrm{P}<0.05 ;{ }^{* *} \mathrm{P}<0.01$
$0.01)$. For example, a statement about the presence or absence of intermittent claudication was made in $99 \%$ of computerised records but only $38^{\circ}$ of standard notes. Table I also shows the proportion of patients in whom a positive response was recorded. Intermittent claudication was recorded in similar proportions of case notes and computer-held records $(1.4 \%$ and $2.9 \%$ respectively). Twelve of the 15 symptoms were recorded more often in the computer-held system, and this difference was significant for both vertigo and depression $(\mathbf{P}<0.001)$.

In the history the number of positive diagnoses was similar between the groups although many more negative past diagnoses were entered in the computer records. The collection of information on a family history of hypertension and the patient's smoking history was also more successful using a structured input. A history of smoking was recorded in $61^{\circ}$ of the computer records compared with $46 \%$ of the standard notes (table I; P $<0.05$ ).

The tendency for the computer system to elicit more information did not hold for all items. Although more key symptoms were recorded using the computer-held record, other symptoms were recorded more often in the standard notes. The average number of currently received drugs was the same in the two groups (1.24 and 1.26 per patient), and there was no significant difference in the number of drugs previously prescribed $(0.7$ per patient for the computer-held records and 0.5 for the controls), although drug history was specifically requested for the computer records. Similarly, although a history of blood pressure recordings was asked for on the computer system an average of $2 \cdot 1$ values per patient were recorded compared with $2 \cdot 4$ per patient in the case notes. The case records included the letter of referral.

The input for the computer system had a physical examination section requesting findings relevant to hypertension on examination of the heart, optic fundi, and peripheral pulses. The computer input was significantly more complete for most physical findings, but positive features were almost identical in the two sets of records.

The records were examined during the one year follow-up. Onehundred-and-fifty-nine drugs were stopped in the computer group and 116 in the control group. The computer record asked for the reason for stopping treatment but this was recorded only in $20.8^{\circ}$ o (33) of cases, a figure not statistically greater than the $11.2 \%$ (13) of the control group. During follow-up more new symptoms were entered on standard notes (average 1.4 per patient-year of follow-up) than in the computer records $(0.9$ per patient-year). On the other hand, more new diagnoses were entered in the computer records $(0.6$ per patientyear than in the case notes $(0 \cdot 1$ per patient-year). Thirty per cent of the computer record diagnoses were of "hypertension" but the remaining $70^{\circ}$ o were generally useful reminders of illnesses and subsequently appeared on all the follow-up input documents. ${ }^{1}$

\section{EFFECTS ON RUNNING OF HYPERTENSION CLINIC}

The output from the computer had to be filed in the patient's notes and the input computer forms sent to the computer centre. Similarly, the system required information on investigation results, which had to be transcribed from internal hospital forms to documents that could be punched at the computer centre. Experience showed that for every 400-500 patients entered into the system one half-time clerk was needed to do this, and doctors at the clinics were not asked to perform these functions.

A survey into consultation times was conducted during the trial, ${ }^{3}$ but it was not known which follow-up patients were in the trial and only the new patients were wholly part of the random sample. The doctors took, on average, eight minutes longer to see a new patient when computer records were used (consultation lasted 39.9 minutes) than when standard notes were used ( 31.4 minutes), but the average time taken for a follow-up consultation was similar in the two groups ( 9.9 and 9.4 minutes respectively).

\section{PATIENT MANAGEMENT DURING TRIAL}

Table II lists the investigations performed during the first three months. The proportion of patients in both groups undergoing certain investigations was small and this is discussed elsewhere. ${ }^{4}$ There was no significant difference between the two groups in the numbers of investigations requested, except for blood glucose estimation, which was requested more often in the group with standard notes. The initial input document included a reminder to perform the investigations with the exception of blood glucose and urinary vanillylmandelic acid estimations. 
TABLE II-Percentage of patients undergoing a particular investigation during first three months and details of management during follow-up

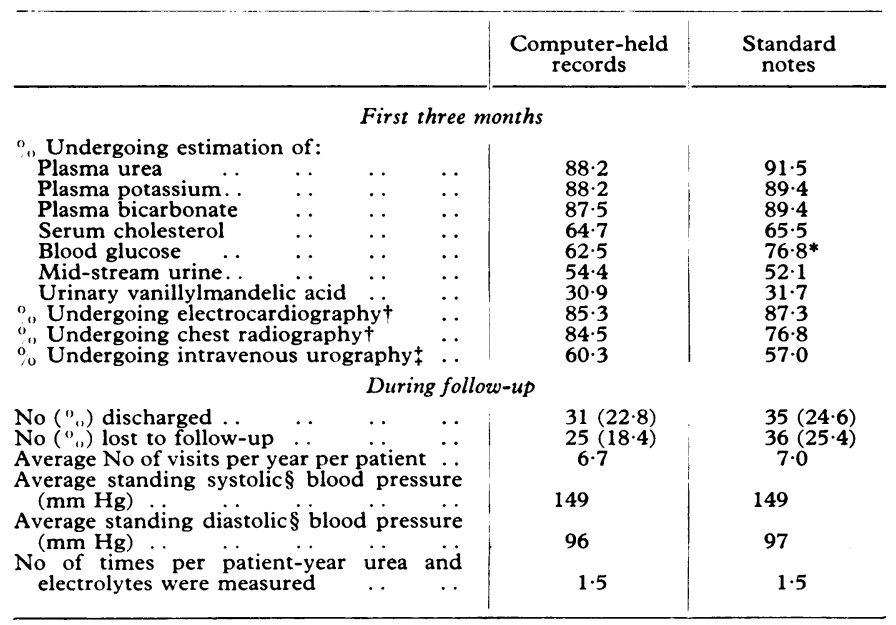

$* \mathrm{P}<0.05$.

+Patient included if investigation performed in year before presentation.

+ Patient included if investigation ever performed.

$\$$ Mean of averages for last three 3-month periods.

Table II also shows the numbers discharged or lost to follow-up in the two groups. The groups did not differ significantly in the numbers discharged or lost to follow-up or in the frequency of consultation. The quality of care, as measured by blood pressure control and the frequency of estimating plasma urea and electrolytes, did not differ between the groups.

\section{Discussion}

The computer system used in this study can replace standard notes $^{1}$ and its value must be judged from two aspects. Firstly, does the system facilitate research, and, secondly, does the use of the computer-held record improve patient management?

For research the computer system has three possible advantages: retrievability of information, completeness of the data, and standardisation. The information stored on the computer is easily retrievable using the present system, ${ }^{2}$ whereas considerable clerical effort is required to retrieve information from standard notes, especially if the records are continually updated. The absence of a record cannot be assumed to imply a negative answer, and the completeness of the data stored on the computerheld records is a definite advantage. Nevertheless, great care is needed in choosing pre-printed questions because the gain in completeness in answering them may be counterbalanced by a reduction in recording of symptoms and signs that are not pre-printed. The deficiencies of the standard record and the lack of completeness of some items on the computer record probably reflected the importance the doctor ascribed to these items, but some of these omissions were disconcerting-for example, the under-recording of information about smoking habits and depressive illness in the standard records. Standardisation is only partially provided by the computer system. Diagnostic habits vary between doctor, and little attempt has been made to standardise diagnoses. Biochemical results, however, are being monitored to access comparability between the centres and these and other investigation results may differ between the centres owing either to unstandardised methods or to the different populations studied.

The comparisons made in the trial did not show any adverse or beneficial effect of the computer system on patient management, although only major changes could have been detected over one year and the patients were not questioned about their opinion of the care provided. The computer system reminds the doctor at every visit of the symptoms present and individual patients may have benefited from these reminders-for example, the drugs prescribed may have been influenced by the reminder. The computer system may possibly have more effect in less specialised clinics.

The system was designed to allow research into only one disease, hypertension, and important items of information were requested. It was initially accepted, however, that the system should be flexible and the set of items contained in the dictionaries is increased as required.

In conclusion, the computer system is proving valuable for research owing to the retrievability and completeness of information, although no improvement in management could be shown in this trial. In contrast, other computer systems have failed because they were not acceptable to the users, ${ }^{5-7}$ whereas the present system, although requiring abbreviation, has been used by more than 40 doctors for four years, 1760 patient records now being held on file. The system is probably so acceptable because it is designed to facilitate patient management. In the light of our experience, however, greatly abbreviated documents for initial and follow-up visits have been designed and much of the information on symptoms, history, and demographic characteristics will be recorded by the patients on selfadministered questionnaires. This will also improve thestandardisation and repeatability of some of the data collected. ${ }^{89} \mathrm{We}$ hope that its acceptability to doctors will thereby be further improved and that the system can also be used in general practice. Other factors contributing to the present success of the system are the limitation to one disease and the use of the batch mode of computer processing. Batch processing is less expensive than real-time computing and allows the hand completion of input documents, which are more easily understood than, for example, a visual display unit. Limitation to one disease and batch processing are also the hallmark of two other successful computer systems. ${ }^{10} 11$

We are grateful to the Nuffield Provincial Hospitals Trust for its support over the last six years and to the Department of Health and Social Security for financial support for the last year. We thank the Wellcome Foundation for the use of office facilities; former members of the programming and medical team-Mr R Stevens, Miss Judith Allen of International Computers Limited, and Mrs Catherine Mearns; Dr R Allen; the staff of the University of London Computer Centre at Queen Mary College; Mr M J R Healy and the Clinical Research Centre at Northwick Park; Drs B Armstrong, S Goldby, and D Pugsley at the Radcliffe Infirmary; Drs D Archer, A Breckenridge, M E Conolly, J Reid, M Myers, C George, P Lewis, M Orme, R Pearson, $M$ Bending, and $R$ Bryant at Hammersmith Hospital; Drs P Yeo, N Woodhouse, and J Labrooy at King's College Hospital; and Mrs A Coburn and our past and present clinic nurses and secretaries.

\section{References}

${ }^{1}$ Beilin, L J, et al, British Medical fournal, 1974, 2, 212.

${ }^{2}$ Coles, E C, et al, Computer fournal, in press.

${ }^{3}$ Organisation and methods/Productivity Services. Oxford Regionl Hospital Board and United Oxford Hospitals. Unpublished Assignment No K89.

${ }^{4}$ Dollery, C T, et al, in preparation

${ }^{5}$ Baird, H W, and Garfunkel, J M, New England Fournal of Medicine, 1965, 272, 1211.

${ }^{6}$ Bennett, A E, and Holland, W W, Lancet, 1965, 2, 1176

? Opit, L J, and Woodroffe, F J, British Medical fournal, 1970, 4, 80.

${ }^{8}$ Bulpitt, C J, Dollery, C T, and Carne, S, fournal of Chronic Diseases, 1974, 27, 309.

${ }^{9}$ Bulpitt, C J, Dollery, C T, and Carne, S, British Heart fournal, in press.

${ }^{10}$ Hedley, A J, et al, British Medical fournal, 1970, 1, 556.

11 Glasgow Blood Pressure Clinic, Fournal of the Royal College of Physicians of London, 1972, 7, 87 . 